\title{
Primary specialisations in Australia: graduates' perceptions of outcome and impact
}

\author{
S. Main ${ }^{1}$ - M. Byrne ${ }^{1}$ (D) J. J. Scott ${ }^{1,2}$ (D) K. Sullivan ${ }^{1}$ (D) A. Paolino ${ }^{1}$ (D) \\ E. V. Slater ${ }^{1} \mathbb{D} \cdot$ J. Boron ${ }^{1}(\mathbb{D}$
}

Received: 1 December 2020 / Accepted: 5 October 2021 / Published online: 4 December 2021

(c) The Author(s) 2021

\begin{abstract}
In 2014, the Australian Government established the Teacher Education Ministerial Advisory Group (TEMAG) to advise on how teacher education programmes could ensure new teachers were adequately prepared for the classroom. Following this, the Australian Government endorsed a key recommendation of the TEMAG Action Now: Classroom Ready Teachers report, the inclusion of specialisations in primary Initial Teacher Education (ITE). This research was conducted at an Australian public university that, in 2016, had embedded specialisations in a revised primary teacher programme structure and was one of the first ITE institutions in Australia to graduate primary teachers with a specialisation. Using a mixed-methods case study design with convenience sampling, this study sought to investigate these primary graduates' perceptions of undertaking a specialisation in relation to the development of content knowledge and pedagogical knowledge in the specialist area, as well as perceived employment advantages. This research took place over 4 years with participants having completed a Bachelor of Education (Primary) at least three months prior to participating. The participants reported benefits to having completed a primary specialisation but expressed concerns about their preparedness to teach their specialisation and whether it would result in any advantages for employment. Recommendations from the participants included teaching practice in their area of specialisation, consideration of specialist skills and changing the timetabling of the specialisation in the programme. Ultimately, there is a need for ongoing research in this area to determine the extent to which primary specialisations deliver the intended outcomes and impacts at both the policy driver level and the university level.
\end{abstract}

Keywords Specialisations $\cdot$ Initial teacher education $\cdot$ Employability $\cdot$ Primary

S. Main

s.main@ecu.edu.au

1 School of Education, Edith Cowan University, 2 Bradford St, Mount Lawley, WA 6050, Australia

2 School of Education and Tertiary Access, University of Sunshine Coast, Sunshine Coast, QLD, Australia 


\section{Introduction}

\section{The focus on initial teacher education}

The Australian education system arguably provides positive educational outcomes for some students (Sahlberg, 2020); however, deficit national and international assessment programme data trends (Hunjan \& Blumer, 2016; OECD, 2019) indicate worrying futures for many Australian students. In particular, students represented by the widening gap between Indigenous and non-Indigenous Australians, urban and rural schools, and school communities with low socio-economic status are more likely to experience poor educational outcomes (De Bortoli \& Thomson, 2010; Lamb et al., 2015; Sullivan et al., 2013; Thomson \& De Bortoli, 2008). Negative trends in international assessment associated with programmes such as the Programme for International School Assessment (PISA) and Trends in International Mathematics and Science Study (TIMSS) have been the impetus for the government to implement initiatives supported by research and act on the reports published by international assessment organisations.

These initiatives include a focus on how initial teacher education (ITE) prepares pre-service teachers (PSTs) to become effective teachers, as the link between effective teaching and successful student outcomes is acknowledged as significant (Barber \& Mourshed, 2007; Hattie, 2003). In particular, pedagogical content knowledge and curriculum content knowledge have long been regarded by researchers as key components of effective teaching (Shulman, 1986). In 2014, the Australian Government established the Teacher Education Ministerial Advisory Group (TEMAG) to advise on how teacher education programmes could better ensure new teacher graduates were classroom ready, that is, prepared to provide the best instructional environment for their students.

An important focus from the TEMAG report Initial Teacher Education in Australia, Action Now: Classroom Ready Teachers (Craven et al., 2014) was on enhancing existing education programmes, including the development of specialised teacher skills. Specifically, recommendation 18 states that, "Higher education providers equip all primary pre-service teachers with at least one subject specialisation, prioritising science, mathematics or a language" (p. xvi).

\section{TEMAG, accreditation standards and specialisation in primary initial teacher education programmes}

The TEMAG report has shaped government policy and the direction of ITE in Australia including the Australian Institute for Teaching and School Leadership (AITSL) who, in 2015, revised the National Program Standards and Procedures for accreditation in response to the TEMAG recommendations (Australian Institute for Teaching \& School Leadership, 2015). Although education is regulated at the state and territory levels, the Australian Institute for Teaching and School Leadership (AITSL) provides leadership in promoting excellence in the profession of teaching and school leadership (AITSL, 2015). A key priority of AITSL is to assist states and territories 
to develop a national approach to accreditation to ensure all ITE programmes are accredited and align with the nationally agreed standards, referred to as the Accreditation Standards and Procedures. These standards and procedures ensure that all graduates of ITE programmes meet the Australian Professional Standards for Teachers (APSTs) at the graduate level.

A timeline for all universities to include primary specialisation in their ITE programmes by 2019 was established by AITSL with Program Standard 4.4 stipulating that, in addition to studying all eight learning areas of the primary school curricula sufficient to enable teachers to teach across all primary years, ITE programmes must provide all primary graduates with a subject specialisation (AITSL, 2019). The specialisations are assessed within the programme, requiring graduates to demonstrate expert pedagogical content knowledge and highly effective classroom teaching in their area of specialisation. The specialisation pathway is intended to equip pre-service primary school teachers with a deeper and broader understanding of a learning area at the graduate level. While the learning areas of mathematics, science and languages have been identified as focus areas for specialisation, AITSL (2019) has also recommended ITE providers consider employer demand and national priority learning areas when selecting primary specialisation offerings within their programmes.

The Review to Achieve Educational Excellence in Australian Schools (Department of Education \& Training, 2017) and The National School Reform Agreement (Department of Education \& Training, 2020) have also promoted an agenda that includes raising the standards and expectations placed on the university sector to provide pre-service teachers with strong pedagogical and curriculum content knowledge and optimise practicum training, particularly in specialist areas such as mathematics, science and literacy.

The accreditation standards afforded universities a level of flexibility in the development and implementation of primary specialisations (Department of Education \& Training, 2020). It is important to note that each Australian university developed and implemented primary specialisations according to their own individual programme, community and stakeholder needs. The following section provides a brief overview of primary specialisations in the Australian context.

\section{Specialisations within primary ITE: an audit of the Australian context}

An audit of the 43 Australian universities found that 33 institutions offer an undergraduate Bachelor of Education (Primary) programme. All programmes offer specialisations as required by TEMAG (2014); however, the learning area specialisations offered differ across the universities. From the information made available in programme handbooks and on university websites, it is evident that variation exists in the learning area specialisations offered. Some programmes have a wider range of learning area choice, whilst others are limited to the areas of science and mathematics as recommended in the TEMAG. Interestingly, languages, which is the third learning area recommended by the TEMAG, is only offered as a specialisation by 13 universities. Overall, the most popular specialisations offered are English and mathematics, with 22 out of the 33 universities offering these options. The next most 
popular is the science specialisation which is offered by 18 universities followed by health and physical education offered by 14 universities. In addition to this, other popular specialisations offered include humanities and social science, the arts, special education, science, technology, engineering and mathematics (STEM), and Catholic education.

The audit discovered, in addition to variance in the learning areas offered as a specialisation, that the number of units PSTs are required to complete within the specialisation also varies. From the information available, it is evident that the required units to complete the specialisation range from one to five units. Another point of difference relates to the unit origin. For example, there are universities that offer the Bachelor of Education (Primary) as part of a specialisation within a broader Bachelor of Arts degree. In these degrees, as well as others, some specialisation units are delivered by schools such as Arts and Humanities, and Business and Economics, which are outside of the School of Education. Whilst this model does allow preservice generalist primary teachers to develop a deep subject matter knowledge in a particular learning area (AITSL, 2017), it does raise the question as to whether they develop the appropriate pedagogical content knowledge to teach it (Even, 1993). This could potentially have an impact on the graduate's ability to effectively teach their specialist area in schools as well as have further impact on their classroom management and instructional quality (König \& Pflanzl, 2016). As stated above, the Review to Achieve Educational Excellence in Australian Schools (2017) and The National School Reform Agreement (2020) aim to raise the standards and expectations of pre-service teachers with the provision of specialisations which will develop strong pedagogical and curriculum content knowledge. The variance in specialist provision offered by Australian universities highlights potential obstacles which need to be considered to ensure quality across all programmes. Whilst this paper presents the narrative of how one Australian university has chosen to implement specialisations into their ITE course, the audit has highlighted that there are broader practicalities which require consideration, in particular, ensuring that specialisations across all Australian universities are delivered by academic staff trained in teaching that area of specialisation (Table 1).

\section{Defining "specialisation"}

Since 2019, as per the national accreditation requirements, all universities in Australia must include specialisations within their ITE programmes. This has led to a growing interest in investigating the efficacy and impact of these offerings. In their analysis of the policy documents leading to the introduction of primary specialisations in Australian ITE, Bourke et al. (2020) assert that there was no evidence that “...introducing primary specialisations will improve confidence, engagement, student enrolments or student outcomes" (p. 734). In addition, they identify the need to clearly define what is meant by a primary specialisation.

The Cambridge dictionary defines 'specialisation' as "the process of concentrating on and becoming expert in a particular subject or skill" (Cambridge Dictionary, 2020). In the education literature, 'specialisation' has been referred to as: (1) 
Table 1 Specialisations offered in Australian Public Universities (2016 and 2020)

\begin{tabular}{lll}
\hline Specialisation & \multicolumn{2}{l}{$\begin{array}{l}\text { Total of } 43 \text { universi- } \\
\text { ties }\end{array}$} \\
\cline { 2 - 3 } & 2016 & 2020 \\
\hline Maths & 6 & 22 \\
English/Literacy & 6 & 22 \\
Science & 5 & 18 \\
HPE & 5 & 14 \\
HASS & 5 & 13 \\
The Arts (inc Visual Arts and Music) & 5 & 12 \\
Special Needs Education & 4 & 11 \\
Languages & 2 & 9 \\
STEM/STEAM & 2 & 7 \\
Technologies & 1 & 6 \\
Catholic Education & 4 & 5
\end{tabular}

generalist teachers with a specialisation; (2) instructional coaches and (3) specialist teachers (Bourke et al., 2020). A specialist teacher in the primary setting is usually a generalist teacher who has additional expertise in a specific area e.g., science (Herbert et al., 2017; Markworth et al., 2016). Herbert et al. identified several roles that these specialist teachers undertook including resourcing, coaching, time release, modelling, team teaching, peer observation, mentoring and independent teaching. Markworth et al. examined the use of specialist teachers to teach either predominantly or wholly in their area of specialisation and identified the benefits and limitations of different models. However, the model put forward by Department of Education and Training (DET) and AITSL for primary specialists describe graduates as "...generalist primary teachers, with a deep focus in a particular learning area" (AITSL, 2017, p. 2). They note that "It is important that these graduates are identified as distinct from specialist teachers who fulfil specialist roles in schools such as librarian or health/physical education" (p.2) “...primary teachers with a specialisation will complement the teachers that they work with by sharing their expertise and skills [but]...this does not mean primary teachers will teach only in their area of specialisation" (DET, 2015, p. 8).

In a study by Mills and Bourke (2020), who interviewed five primary pre-service teachers about their experience of undertaking a specialisation in science, this distinction appears to be poorly understood. The pre-service teachers were generally unclear on how their specialisation would influence their teaching situation, but three of the five respondents indicated that they expected to be responsible for this area in the schools in which they would be teaching (p. 33). They also expressed concern about how more established teachers might respond to their 'specialist' title, indicating that they expected to be identified as a subject expert. Other findings from this research included the participants reporting that the modules they undertook for the science specialisation enhanced their pedagogical knowledge in this area, but they found the requirement to do this in addition to the existing course work to be onerous. Despite their concerns, 
these pre-service teachers were confident that their science specialisation would have a positive impact on their future employment (Mills \& Bourke, 2020).

\section{Primary specialisations: policy implementation to school application}

Implementation of policy involves federal, state and school sectors (Shaw, 2020) as well as key stakeholders including principals, teachers, parents and community members (Viennet \& Pont, 2017). Weaver-Hightower (2008) highlighted the need to consider an ecological perspective when examining policy implementation, noting that there is a range of factors that influence policy development and implementation. Time was also identified as a factor in the 'passing-down' of policy implementation. In their Organisation for Economic Cooperation and Development (OECD) report on the time lag in curriculum change, Halinen (2017) identified four areas where time lag occurred: recognition lag, seeing the need for change; decision-making lag, planning for change; implementation lag, the speed at which changes are adopted into practice; and, impact lag, when the results of change become evident. ITE providers may respond quickly to mandates from AITSL but this may not immediately translate into an uptake or even understanding of these changes in schools, resulting in implementation lag. In evaluating implementation, we must also consider the impact of all stakeholders (WeaverHightower) and how their interpretations of the policy's goals may differ (Spillane et al., 2002). The audit of how Australian ITE providers are implementing primary specialisations indicates a varied approach to meeting the needs of their individual programme contexts, which is consistent with the flexibility afforded by the accreditation requirement. Further research stemming from the implementation of specialisation policy is needed to provide greater clarity on the effectiveness of the initiative in addressing teacher quality concerns and supporting the need for specialisation in the primary context (Bourke et al., 2020).

The research described in this paper examines ITE graduates' perceptions of the primary specialisations offered in their undergraduate programme. Conducted across 4 years, the research examined the extent to which a primary ITE programme with specialisations at an Australian public university has delivered the intended outcomes. The public university where this research took place is located in a large urban area and was one of the first institutions in the country to graduate primary teachers with a specialisation. This occurred in 2016, with specialisation units formally recognised on the student parchment and transcript. It was envisaged that this would have implications for future employability prospects and opportunities. The below sections provide the aims, methodology and result of the study. This is followed by a discussion of the results, conclusions and opportunities for future research.

\section{Aims}

The purpose of this research was to investigate graduates' perceptions of the extent to which a primary ITE programme with a specialisation offering has delivered the intended outcomes and impacts, being: 
Table 2 Participant's primary specialisation pathways $(N=33)$

\begin{tabular}{ll}
\hline Specialisation & $n$ \\
\hline Arts & 4 \\
Catholic Studies & 5 \\
English & 2 \\
Health and Physical Education & 2 \\
Humanities and Social Sciences & 4 \\
Mathematics & 6 \\
Science & 5 \\
Special Education & 5 \\
\hline
\end{tabular}

(1) Increase in expert content knowledge, pedagogical content knowledge and highly effective classroom teaching for their area of specialisation as a result of undertaking the primary specialisation.

(2) Recruitment advantages and employability.

(3) An appropriate structure for delivery of the specialisation units.

\section{Methods}

This research used case study design (Hamilton \& Corbett-Whittier, 2012) with convenience sampling. Mixed methods were employed to collect both quantitative and qualitative data, as this has been shown to be a powerful way to broaden and deepen understandings of phenomena (Turner et al., 2017). Quantitative and qualitative measures were used to enable triangulation of data which assisted in validating the findings (Turner et al., 2017). Johnson et al. (2007) suggest that the use of mixedmethods research is primarily a pragmatic approach to knowledge recognising that consideration of multiple viewpoints is required to fully understand a situation.

\section{ITE programme structure}

The case study university offers eight specialisation pathways as part of its Bachelor of Education - Primary ITE programme. Table 2 below shows the specialisations pathways of participants involved in this study. All units in this programme are offered in on campus and off campus (fully online) modes and students can elect to undertake units in either mode. In the final year of their programme, PSTs complete a total of four specialisation units across the year (one unit in semester one and three units in semester two) although some specialisations were offered in the Summer or Winter school teaching periods.

\section{Study design}

Once approval to conduct this research was granted by the relevant University Human Research Ethics Committee, data collection commenced. Convenience 


\section{Do you think the knowledge and skills you have obtained through your specialisation have....}

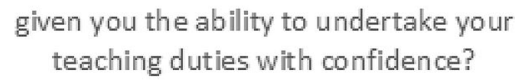

increased your ability to meet the educational needs of your school?

given you the confidence to teach your specialisation?

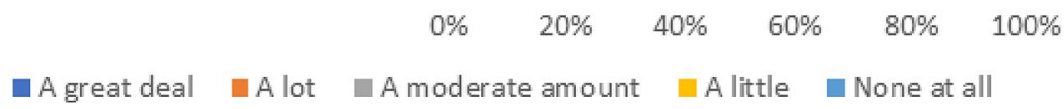

Fig. 1 Perceived knowledge and skills obtained through completing a specialisation $(n=21)$

sampling was used to recruit participants who had graduated from the case study university. Quantitative questionnaire data, qualitative interviews and text responses from the questionnaire, were collected to ensure a comprehensive exploration of the research questions and provide a detailed view of the graduates' experience of specialisation (Cohen et al., 2011; Creswell, 2013).

This research took place over 4 years and involved two phases of data collection:

- Phase 1 (2016-2017): Data collected via online questionnaire and one-on-one interviews.

- Phase 2 (2018-2019) Data collected via one-on-one interviews.

The non-demographic questions for these phases are presented in Figs. 1 and 2.

Phase 1 ITE graduates $(n=266)$ from the case study university were invited via email to participate in this study. Documentation was sent to potential graduate participants' current contact details provided by the university's Student Services and Alumni. Where it was found that a current email address was not held, a hard copy letter of invitation was mailed to the potential participant's home address. Participants were selected on the basis that they had been enrolled in a Bachelor of Education (Primary) programme with a specialisation unit set and graduated mid-year 2016, end-year 2016 or mid-year 2017. A link was provided in the communication that directed the participant to an online consent form and Qualtrics questionnaire. Follow-up recruitment emails were sent to graduates on two subsequent occasions. A total of 21 consented to participate in this phase of the study (males $n=4$; females $n=17 ; n=10 \leq 24 \mathrm{yrs}$ old; $n=11 \geq 25 \mathrm{yrs}$ old). On completion of the questionnaire, participants were invited to participate in a face-to-face interview.

Online questionnaire Participants were asked to complete a 15-20 minute online Qualtrics questionnaire exploring their perceptions of the primary specialisation 
How much do you agree that your specialisation has.......

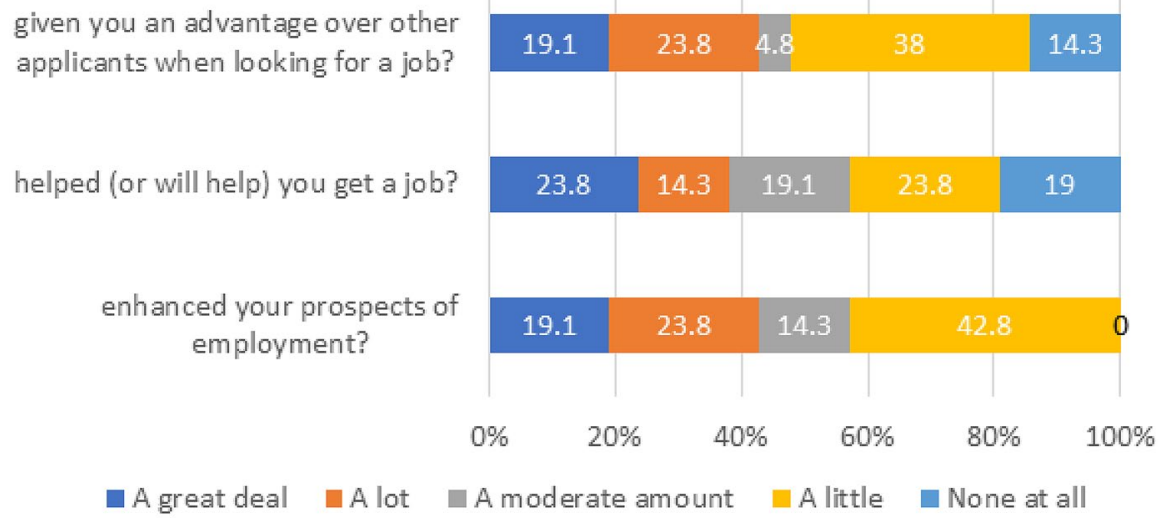

Fig. 2 Importance of primary specialisation for teaching career $(n=21)$

programme and employability on graduation. The questionnaire was designed by the research team for the purposes of this study. As the questionnaire was deployed online, participants were able to undertake the questionnaire asynchronously, at a time that was convenient to them. The questionnaire consisted of 15 questions but six of these questions were dependant on responses to other questions. Questions included age, gender, specialisation, employment status and their perceptions of whether the knowledge and skills gained through the specialisation were worthwhile and contributed to their employability. Non-demographic questions, which focused on participant perceptions, were reported on a 5-point Likert scale with responses ranging from: $1=$ not at all, $2=\mathrm{a}$ little, $3=\mathrm{a}$ moderate amount $4=\mathrm{a}$ lot and $5=\mathrm{a}$ great deal.

Interviews A total of six graduates who agreed to an interview met at a mutually convenient time with the researcher. Interviews were completed face to face or via phone depending on participant availability and location. In the interviews, participants were asked to reflect on whether the specialisation:

- Added value to the graduate experience

- Prepared them to teach the content

- Was important for their future career

- Was appropriately delivered and structured as part of the programme.

Phase 2 In 2018 and 2019 graduating PSTs $(n=396)$ were invited to participate in post-graduation interviews whilst still enrolled in the Bachelor of Education (Primary). They were asked to provide contact details where they could be contacted three to six months after graduation if they were willing to be interviewed.

Interviews A total of 17 PSTs agreed to participate in-depth interviews but only 12 (males $n=2$; females $n=10 ; n=2 \leq 24$ yrs old; $n=10 \geq 25 y$ rs old) were available at the time of interviewing, post-graduation. Consistent with Phase 1, interviews 
were completed face-to-face or via phone depending on participant availability and participants were asked to reflect on whether the specialisation:

- Added value to the graduate experience

- Prepared them to teach the content

- Was important for their future career

- Was appropriately delivered and structured as part of the programme.

\section{Analysis}

Quantitative electronic survey data were collected and entered into SPSS for frequency and descriptive analysis. Interview data were transcribed verbatim and subjected to repeated readings and constant comparisons against a priori themes that provided a framework into which data was organised (Miles et al., 2014; Neville $\&$ Whitehead, 2020). The purpose of this type of analysis is to identify concepts or themes present or absent in the data that would enable the researchers to answer the research aims.

\section{Results}

The combined sample for Phase 1 and 2 was 33 participants (males $n=6$; females $n=27 ; n=12 \leq 24 y$ rs old; $n=21 \geq 25 y$ rs old). A summary of results is provided below for both Phase 1 and 2 .

\section{Phase 1 and 2: Responses from the questionnaire and interview data on employment (2016-2019)}

The 21 participants who completed the questionnaire in 2016-2017 and the 12 participants who were interviewed in 2018-2019 were asked whether they had been employed since graduation and in what capacity. This information was considered important in the context of participants' answers to questions on the outcomes of completing the specialisation, particularly in relation to employment.

In the 3 to 6 months post-graduation, $69.7 \%(n=23)$ of the participants reported that they had teaching work, although only five of these graduates had secured fulltime employment (two in regional areas of the state and three in the metropolitan area). Two participants had part-time work with the remainder reporting they were working as relief or casual staff. For the participants who were currently working, the majority $(81.8 \% ; n=9)$ were working at Department of Education sites and two (18.2\%) were working with Catholic education. Six (42.9\%) participants reported that they were using their specialisation in their current teaching position, two each with specialisations in special education, Catholic education and science. Most of the participants who did not have ongoing appointments at the time of this questionnaire $(84.85 \% ; n=28)$ were looking for work as a teacher, with 22 looking for full-time permanent or contract employment, three looking for part-time $(n=1)$ or 
relief/casual work $(n=2)$ and 8 participants who did not respond to this question. One participant was not looking for teaching work and did not provide any further qualification.

\section{Phase 1: (2016-2017) Questionnaire data}

During 2016 and 2017, 21 participants completed the questionnaire in Qualtrics related to their perceptions of the outcomes and impact of completing the specialisation.

\section{Participants' perceptions of knowledge and skills gained through completing a specialisation}

When asked about the impact of the knowledge and skills they gained from completing their specialisations, participants reported it was important for their confidence as teachers $(47.6 \%)$ 'a lot' or 'a great deal' $(M=2.8, m d n=3, S D=1.4)$, but only $42.9 \%$ reported that their studies gave them the confidence to teach their specialisation 'a lot' or 'a great deal' $(M=2.8, m d n=3, S D=1.3)$. The majority of participants (52.4\%) felt that the knowledge and skills they had obtained through completing their specialisation increased their ability to meet the educational needs of the children at their school 'a lot' or 'a great deal' $(M=2.8, m d n=2, S D=1.3)$.

\section{Participants' perceptions of the importance of their specialisation for their teaching career}

When asked about whether their specialisation provided an advantage when seeking employment, $42.9 \%$ of participants responded that their specialisation gave them either 'a great deal' or 'a lot' and $4.8 \%$ said there was 'a moderate amount' of advantage over other applicants. Of the remaining respondents, $38 \%$ felt it provided 'a little' advantage and $14.3 \%$ responded there was no advantage at all $(M=3$, $m d n=4, S D=1.4$ ). The majority of participants reported that having the specialisation had helped, or would help, them get a job to some extent with $57.2 \%$ indicating it would have at least 'a moderate amount' to 'a great deal' of effect $(M=3, m d n=3$, $S D=1.5)$. Similarly, the majority responded that having a specialisation had been more than 'moderately' advantageous in gaining employment (57.2\%) $(M=2.8$, $m d n=3, S D=1.2$ ).

\section{Phase 1 and 2: Written text responses from the questionnaire and interview data (2016-2019)}

Qualitative analysis of written text responses from the questionnaire and interview data was completed. The written text responses in the questionnaire provide the opportunity to further explore the quantitative data. Twelve graduates participated in the interviews and six graduates who participated in the questionnaire included text responses in the questionnaire $(n=18)$. 


\section{Perceived advantage of the primary specialisation}

Nine participants indicated that they perceived having a specialisation as a definite advantage when applying for work. General comments included: "The more things you can put to your name I think the better your chances are of getting a job, really" (G1) and "I feel like it does provide some extra bonus provided you have the right specialisation; so, what that particular school is looking for" (G2). One participant reported that having their specialisation on their Curriculum Vitae $(\mathrm{CV})$ had afforded them the advantage of being more highly rated for interviews:

When I applied for the school here... having that qualification on my CV put me at the top. They had a whole lot of CVs. They had some people with experience in teaching, but no one had the specialisation.... And they called me in [for an interview] ... It's a bonus really, to give you that edge. (G3)

Three participants reported that their specialisation was directly responsible for their teaching appointments, elaborating on how their specialisation related to their employment: "I have received many jobs offers for science teacher... I believe that having a specialisation is a distinct advantage in getting a job". (G4), "I've had teaching relief work in special needs schools that I may not have obtained if my testamur had not said 'Specialisation in Special Education"" (G5) and "I haven't been employed in that area [special education], but I was employed [in a regular school] because I knew how to teach evidence-based direct instruction" (G6).

Other participants felt that their specialisation may not assist them in finding work initially but would continue to be of value throughout their careers as they would be able to teach as a generalist or specialist teacher, thereby adding value to their teaching degree and future prospects for full-time employment. Two participants indicated that they may be able to work in their area of specialisation later: "Later down the track I think you will benefit, and I'll be able to be prioritised for those positions to grow in that direction [area of specialisation]" (G7) and "In the STEM area, because a lot of what schools are looking at doing at the moment, especially in the next couple of years, it will be a very employable aspect to have on my CV" (G8). Another participant felt that the specialisation did not prepare them to be a specialist in that area but would indicate to schools the area they were interested in and, potentially, provide opportunities to teach in that area: "The specialist units for HASS did not equip me to teach the subject better than a normal grad; however, when people ask about my specialisation they know it is a subject I am passionate about" (G9).

Other participants, however, could not see any benefit to completing specialisation units. Some participants reported that it did not provide any advantage when seeking employment: "[I was] no better prepared than any other grad who did not specialise" (G10) and, "I gained employment through my performance on a practicum. The school's priority is maths and English so having a science specialisation means nothing" (G11). Whereas others expressed concern about their preparedness to teach a specialisation: "We need to have more experience teaching kids to do 'that' - not so much just doing it ourselves" (G12), "I don't feel qualified to apply [for a specialist job]" (G13), "I don't think anyone would be getting a job straight 
out in their specialisation. They're just not qualified enough really" (G14), "If I felt more prepared, it would be something awesome to have on your transcript, and to be able to be really confident [that] I can do it. Whereas right now... I'd probably panic" (G15) and, "[I have] no idea how to write a lesson or unit plans [for my specialisation]" (G16).

Participants also expressed concern about the school's expectations of them: "I am concerned that a school will see that I have a specialisation in mathematics and expect me to be knowledgeable about best practice mathematics education, about a range of mathematics programs and what works best in the classroom" (G13), "Currently, being a fresh graduate being in charge of like a specialisation of whole school science. I'm a little bit concerned about that" (G17) and, "I just would be frightened of them [schools] expecting me to know more about it [my specialisation]" (G12).

For some, particular concern was expressed about their ability to teach certain specialisations that require specific skills such as arts (drama skills, ability to read music, draw). One student reported "Music was great, it's such a specialist area, but I feel like I wouldn't have the confidence to go for a job in the music area. It needs to be a specialist area on its own."(G18). This contrasts with the perception of participants who had prior experience in their area of specialisation. For example, two participants with the physical education specialisation were more confident about their ability to meet schools' requirements and contribute to the community because they had prior experience with community sport and could be involved in required activities such as after-school sports and inter-school sports days. There was also some mention $(n=2)$ of the need to give PSTs some guidance about what the best specialisation for them would be, based not only on job prospects but also on the individual's interests, skills and abilities.

As a component of research question two, in trying to identify the perception of how schools view and value specialisations, the 12 interview participants in Phase 2 were asked if the schools made any comments on their specialisation. Only one participant reported receiving any feedback, "I was told that being a science specialist and being a female could be very good" (G4). Unsurprisingly, the nine graduates who perceived that a specialisation was advantageous to them also said they would choose the specialisation again and would also recommend the specialisation pathway to PSTs, whilst those who felt there was no advantage to completing a specialisation did not.

\section{Delivery model for specialisations}

Participants commented on several aspects of the content and delivery of the specialisation units but a major theme that emerged from the interviews was around the timing of the specialisation units. This was mentioned throughout the interviews in response to several of the questions asked of participants, emphasising this issue has had an important influence on graduate's perceptions of the benefits of completing a primary specialisation pathway.

Several participants who undertook their specialist units during winter or summer school felt that they were rushed and that they did not get the opportunity to incorporate their learning into practice. Whereas others who completed the 
specialisation units in the standard unit structure, after their final Assistant Teacher Program (ATP), felt that the timing of the specialist units had impacted on their ability to get work as they were unable to leverage off their ATP whilst still connected to the school: "You need your ATP to be the last thing you do, then you can go off and work" (G7), "After ATP [I was] unable to take relief or a job while still in the school's memory because of remaining specialist units to be completed" (G14) and, "So, we'd finished our final assessment and then we had to go back to Uni for eight weeks, and, in that eight weeks, do backwards stuff" (G10). These participants stated that specialisation units should commence earlier in the degree and it was suggested that specialisation be completed prior to their ATP, ideally in third year, so that this learning can be utilised in the final practicum: "and you would have been more exposed to it. If I had done them [specialist units] in, say, third year, come ATP I would have been like. 'Well, I'm a specialist now-I'll go out and do it'” (G1).

Most of the graduates were adamant that they needed practical experience of teaching their specialisation. Three participants suggested including a practicum as part of the specialist unit set: "We need a prac for our specialisation, absolutely, even if it's just one short one" (G16). In summary, recommendations included an additional practicum in their area of specialisation (e.g. 2-5 weeks) or completing their final practicum in a school that offered their area of specialisation, which is consistent with the recommendations of the Department of Education and Training (2017, 2020).

\section{Discussion}

While most participants from this large urban public university perceived there were benefits to having completed a primary specialisation and having this on their university parchment and $\mathrm{CV}$, they were concerned about not being able to put that specialisation into practice prior to graduation in a professional experience context. Some participants suggested that specialisation units should commence earlier in the degree, which is consistent with previous research on specialisations (Xaba, 2017). Further, there was a disparity between participants' perception of specialisations as offering an advantage to prospective employment and the positive personal benefits they could bring to the quality of teaching and learning within a school. Participants were more positive in response to questions on confidence to teach, ability to meet the needs of a school and applying specialisation knowledge compared to their perspectives on the advantage over others, help getting a job and enhanced prospective employment. Despite these reservations, six of the 33 respondents directly attributed their specialisation to their employment.

In some cases, participants' expectations about the specialisation programme were not met and they felt they did not have the confidence to teach in their specialist area. Although some participants reported that this was influenced by the area of specialisation and their previous training, knowledge and experience with their particular area, rather than what they had learned during their studies. What was evident in the participants' responses was the perception that their specialisation was training them to undertake roles similar to those identified by Markworth et al. 
(2016), whereby they would be predominantly or wholly teaching in their area of specialisation. This misconception could also be proliferated by the wording of the questions such as 'Do you think the knowledge and skills you have obtained through your specialisation have given you the confidence to teach your specialisation?', It is not surprising that less than half of the participants (42.9\%) felt confident to teach in their area of specialisation if they were expecting this to mean they would be curriculum leaders upon graduation. It is interesting to note that participants were the most confident in response to the question of whether completing the specialisation increased their ability to meet the educational needs of their school (52.4\%) as this is aligned to the stated intent of AITSL and DET. Primary graduates with a specialisation are expected to complement the teachers they work with by bringing a greater depth of knowledge in one area, but are still generalist teachers (DET, 2015, p. 8).

Participant perception of a lack of interest from schools in their specialisation may stem from factors including implementation and impact lag referred to by (Halinen, 2017), and graduation of participants prior to the requirement for specialisation in primary ITE to commence in 2019. This could contribute to a lack of awareness in schools about what this specialisation on the graduate's transcript might mean or concern about whether a new graduate could undertake a specialist role, based on the existing model of specialist teachers in schools who teach predominantly in that area. The case study university in this research responded quickly to mandates from AITSL but this does not immediately translate to an uptake or even understanding of these changes in schools. The lack of feedback from schools on their specialisations when applying for work left many of the graduates with the impression that specialisations were not valued by schools. As the research on policy implementation identifies, there is often a lag between the decision to implement a change and the uptake of this change by key stakeholders (Phillips \& Ochs, 2003). This highlights the need for ITE providers to take on more of an advocacy role when clearly communicating changes in accreditation requirements that have implications for key stakeholders. Particularly in relation to the requirement for primary specialisation and their importance as outlined in Program Standard 4.4 (AITSL 2019).

There is evidently still more work to be done in terms of what specialisations in ITE are intended to achieve and how they are structured to achieve this. WeaverHightower (2008) suggests that ITE providers need to be aware of "the impact that each actor has in shaping the focal policy" (p. 158) and, in the case of primary specialisations, this can be different stakeholders proliferating incorrect understandings of what specialisations are intended to achieve. As the audit of primary specialisation offerings illustrated, there are a range of specialisation offerings and pathways within ITE programmes. While this may reflect flexibility of ITE providers to meet the needs of their community it is apparent there are some clear differences in volume of learning offered which may impact the effectiveness of Primary ITE specialisations. The case study university where this research took place incorporated the four units of specialisation into the programme structure. This structure provided its PSTs with the opportunity to develop expert pedagogical content knowledge and highly effective classroom teaching at the graduate level in their area of specialisation. However, it is to be acknowledged that this structure may not be appropriate or applicable in other university or ITE provider contexts. 
The study was one of the first of its kind and provides useful data on the mandated primary specialisations within Australian ITE programmes. While this study has noted strengths, it also has noted limitations. Response rates to surveys and interviews were lower than anticipated with only 21 graduates $(8 \%)$ completing the questionnaire and 6 (2\%) participating in the interviews; however, this is consistent with previous studies using university student samples that have shown similar low response rates (Bennett et al., 2006; Porter \& Umbach, 2006; Tanudjaja et al., 2020). The sample was also relatively homogenous, being from one Australian public university. These factors limit the generalisability of the findings. Further, the timing of the research has implications for the participants' responses as they were newly graduated and may not have had time to see any potential benefits the specialisation might afford them. Despite these limitations, these data provided some important information for the researchers on the experiences of the participants when undertaking the primary specialisation units and when seeking employment. Similar research in other ITE institutions could provide valuable information on how student perceive the content and delivery of their specialisations and whether it is suitable for their context.

\section{Conclusion}

The findings from this study indicate that most participants felt they increased their knowledge and skills in a specialist area by completing a specialisation. However, many felt that they lacked preparedness and confidence to teach the specialisation area. There was consistent discussion among participants that they required more training in their specialist area within the ITE programme and that they lacked inschool experience (placement days) in their chosen area. However, most participants were positive about their ITE specialisation and experience and felt that having a specialisation increased their employability. Some participants felt that prospective employers (schools' leaders) lacked interest or awareness of the specialisation within the ITE programme, and this may have affected employability. This may be a result of the primary specialisation ITE mandate only being a relatively new requirement. Many participants were not satisfied with the structure of the ITE programme with most indicating that specialisation units should commence earlier in the degree. As this research was only conducted within one university, there is a need for further research to investigate the implementation of specialisations in other ITE programmes across Australia. Further research in this area is warranted to determine the extent to which primary specialisation in ITE deliver the intended outcomes and impacts at both the policy and university level.

Funding This research was funded by Strategic Initiative Funds 32326.

Data availability The data that support the findings of this study may be made available on request from the corresponding author. The data are not publicly available due to ethical restrictions. 


\section{Declarations}

Conflict of interest There were no conflicts of interest or competing interests.

Ethics approval Ethics approval for the research, including the method of dissemination, was sought and received from the Edith Cowan University Human Research Ethics Committee. Ethics Number 17189. We thank the study participants for their contribution to the research.

Open Access This article is licensed under a Creative Commons Attribution 4.0 International License, which permits use, sharing, adaptation, distribution and reproduction in any medium or format, as long as you give appropriate credit to the original author(s) and the source, provide a link to the Creative Commons licence, and indicate if changes were made. The images or other third party material in this article are included in the article's Creative Commons licence, unless indicated otherwise in a credit line to the material. If material is not included in the article's Creative Commons licence and your intended use is not permitted by statutory regulation or exceeds the permitted use, you will need to obtain permission directly from the copyright holder. To view a copy of this licence, visit http://creativecommons.org/licen ses/by/4.0/.

\section{References}

Australian Institute for Teaching and School Leadership. (2015). Accreditation of initial teacher education programs in Australia: Standards and procedures 2015. AITSL. https://www.aitsl.edu. $\mathrm{au} /$ docs/default-source/initial-teacher-education-resources/accreditation-of-ite-programs-in-austr alia.pdf

Barber, M., \& Mourshed, M. (2007). How the world's best-performing school systems come out on top. McKinsey \& Company. https://www.mckinsey.com/industries/public-and-social-sector/our-insights/ how-the-worlds-best-performing-school-systems-come-out-on-top\#

Bennett, L., Nair, C. S., \& Wayland, C. (2006). Love it or hate it: Participation a key ingredient in closing the loop. Australian Universities Quality Forum.

Bourke, T., Mills, R., \& Siostrom, E. (2020). Origins of primary specialisation in Australian education policy: What's the problem represented to be? The Australian Educational Researcher, 47(5), 725740. https://doi.org/10.1007/s13384-019-00370-y

Cambridge Dictionary. (2020). Retrieved November 27, from https://www.lexico.com/definition/speci alization

Cohen, L., Manion, L., \& Morrison, K. (2011). Research methods in education (7th ed.). Routledge.

Craven, G., Beswick, K., Fleming, J., Fletcher, T., Green, M., Jensen, B., Leinonen, E., \& Rickards, F. (2014). Action now: Classroom ready teachers-Report of the Teacher Education Ministerial Advisory Group (TEMAG). Australian Government, Department of Education and Training. https:// www.dese.gov.au/teaching-and-school-leadership/resources/action-now-classroom-ready-teach ers-report-0

Creswell, J. W. (2013). Research design: Qualitative, quantitative, and mixed methods approaches (4th ed.). Sage.

De Bortoli, L., \& Thomson, S. (2010). Contextual factors that influence the achievement of Australia's Indigenous students: Results from PISA 2000-2006. Australian Council for Educational Research. https://research.acer.edu.au/ozpisa/7

Department of Education and Training. (2017). Review to achieve educational excellence in Australian Schools. https://www.dese.gov.au/quality-schools-package/resources/review-achieve-educationalexcellence-australian-schools

Department of Education and Training. (2020). National School Reform Agreement. Australian Government. https://www.dese.gov.au/quality-schools-package/resources/national-school-reform-agree ment 
DET. (2015). Action now: Classroom ready teachers - Australian Government response. Department of Education. https://docs.education.gov.au/documents/australian-government-response-action-nowclassroom-ready-teachers-report

Even, R. (1993). Subject-matter knowledge and pedagogical content knowledge: prospective secondary teachers and the function concept. Journal for Research in Mathematics Education, 24(2), 94-116. https://doi.org/10.5951/jresematheduc.24.2.0094

Halinen, I. (2017). Managing the time-lag dilemma. Internal report prepared for the OECD2030 study. OECD.

Hamilton, L., \& Corbett-Whittier, C. (2012). Using case study in education research. SAGE Publications.

Hattie, J. (2003). Teachers make a Difference, What is the research evidence? 2003 - Building Teacher Quality: What does the research tell us?, Melbourne, Australia. http://research.acer.edu.au/research_ conference_2003/4

Herbert, S., Xu, L., \& Kelly, L. (2017). The changing roles of science specialists during a capacity building program for primary school science. Australian Journal of Teacher Education, 42(3), 1-21. https://doi.org/10.14221/ajte.2017v42n3.1

Hunjan, R., \& Blumer, C. (2016, 7 December). Australian schools are in 'Absolute decline' globally, says PISA report. $A B C$.

Johnson, R. B., Onwuegbuzie, A. J., \& Turner, L. A. (2007). Toward a definition of mixed methods research. Journal of Mixed Methods Research, 1(2), 112-133. https://doi.org/10.1177/1558689806 298224

König, J., \& Pflanzl, B. (2016). Is teacher knowledge associated with performance? On the relationship between teachers' general pedagogical knowledge and instructional quality. European Journal of Teacher Education, 39(4), 419-436. https://doi.org/10.1080/02619768.2016.1214128

Lamb, S., Jackson, J., Walstab, A., \& Huo, S. (2015). Educational opportunity in Australia 2015: Who succeeds and who misses out. Centre for International Research on Education Systems. https://doi. org/10.4226/80/5993e4d6c016c

Markworth, K. A., Brobst, J., Ohana, C., \& Parker, R. (2016). Elementary content specialization: Models, affordances, and constraints. International Journal of STEM Education, 3(1), 1-19. https://doi.org/ 10.1186/s40594-016-0049-9

Miles, M. B., Huberman, A. M., \& Saldaña, J. (2014). Qualitative data analysis: A methods sourcebook (3rd ed.). SAGE Publications.

Mills, R., \& Bourke, T. (2020). Primary specialisation in Australian education: Pre-service teachers' lived experiences. In J. Fox, C. Alexander, \& T. Aspland (Eds.), Teacher education in globalised times. Springer. https://doi.org/10.1007/978-981-15-4124-7

Neville, S., \& Whitehead, D. (2020). Analysing data in qualitative research. In D. Whitehead, G. LoBiondo-Wood, \& J. Haber (Eds.), Nursing \& midwifery research: Methods and appraisal for evidencebased practice (5th ed., pp. 136-155). Elsevier.

OECD. (2019). PISA 2018 results (Volume I). Organisation for Economic Cooperation and Development. https://doi.org/10.1787/5f07c754-en

Phillips, D., \& Ochs, K. (2003). Processes of policy borrowing in education: Some explanatory and analytical devices. Comparative Education, 39(4), 451-461. https://doi.org/10.1080/030500603200016 2020

Porter, S. R., \& Umbach, P. D. (2006). Student questionnaire response rates across institutions: Why do they vary? Research in Higher Education, 47(2), 229-247.

Sahlberg, P. (2020). Are Australian students receiving the school education they deserve? ABC News. https://www.abc.net.au/news/2020-03-09/education-policy-learning-problem-australia-schoolingfunding/12034350

Shaw, R. D. (2020). Finding footprints: Analyzing arts education policy implementation. Arts Education Policy Review, 121(1), 1-9. https://doi.org/10.1080/10632913.2018.1530711

Shulman, L. S. (1986). Those who understand: Knowledge growth in teaching. Educational Researcher, 15(2), 4-14.

Spillane, J. P., Reiser, B. J., \& Reimer, T. (2002). Policy implementation and cognition: Reframing and refocusing implementation research. Review of Educational Research, 72(3), 387-431. https://doi. org/10.3102/00346543072003387

Sullivan, K., Perry, L. B., \& McConney, A. (2013). How do school resources and academic performance differ across Australia's rural, regional and metropolitan communities? The Australian Educational Researcher, 40(3), 353-372. https://doi.org/10.1007/s13384-013-0100-5 
Tanudjaja, S. A., Chih, H., Burns, S., Crawford, G., Hallett, J., \& Jancey, J. (2020). Alcohol consumption and associated harms among university students in Australia: Findings from a cross-sectional study. Health Promotion Journal of Australia. https://doi.org/10.1002/hpja.342

The Australian Institute of Teaching and School Leadership. (2019). Accreditation standards and procedures. https://www.aitsl.edu.au/deliver-ite-programs/standards-and-procedures

Thomson, S., \& De Bortoli, L. (2008). Exploring scientific literacy: How Australia measures up. Australian Council for Educational Research. https://research.acer.edu.au/ozpisa/2

Turner, S. F., Cardinal, L. B., \& Burton, R. M. (2017). Research design for mixed methods: A triangulation-based framework and roadmap. Organizational Research Methods, 20(2), 243-267. https://doi. org/10.1177/1094428115610808

Viennet, R., \& Pont, B. (2017). Education policy implementation: A literature review and proposed framework. Organisation for Economic Cooperation and Development. https://www.oecd-ilibrary. org/content/paper/fc467a64-en

Weaver-Hightower, M. B. (2008). An ecology metaphor for educational policy analysis: A call to complexity. Educational Researcher, 37(3), 153-167. https://doi.org/10.3102/0013189X08318050

Xaba, V. M. (2017). The perspective of educationists in the adoption of a specialist approach in teaching at primary school level in Swaziland: Focus on the Manzini region [Masters of Education, University of Kwazulu-Natal]. https://ukzn-dspace.ukzn.ac.za/handle/10413/15785

Publisher's Note Springer Nature remains neutral with regard to jurisdictional claims in published maps and institutional affiliations.

S. Main is a Senior Lecturer in Education at Edith Cowan University in Western Australia. Her teaching and research interests include preparing pre-service and in-service teachers to teach children with diverse abilities, including evidence-based approaches to literacy instruction, managing challenging behaviour, and using technology to facilitate learning.

M. Byrne is the Associate Dean (Primary) for the School of Education at Edith Cowan University. Matt is an experienced teacher, teacher educator and researcher. He is involved in Aboriginal education and research and the development of cultural competency within the university, public and private sector. Matt is an Honorary Research Fellow with the Telethon Kids Institute working with Professor Donna Cross and the Health Promotion and Education Research group.

J. J. Scott is a Lecturer in Curriculum and Pedagogy, Health and Physical Education and is the Program Coordinator of the Master of Teaching (Secondary) in the School of Education and Tertiary Access, University of Sunshine Coast, QLD, Australia. He is an adjunct lecturer for the School of Education at Edith Cowan University and is the President of the Australian Council for Health, Physical Education and Recreation: Western Australia (ACHPER WA). He completed his PhD within the Priority Research Centre in Physical Activity and Nutrition at the University of Newcastle. His research interests include: physical activity (measurement and promotion), physical literacy, teacher education, Health \& Physical Education pedagogy and curriculum.

K. Sullivan is a Senior Lecturer of Primary Mathematics and Technology at Edith Cowan University. Across a 25-year career he has fulfilled many roles and taught in a broad spectrum of learning environments, spanning from early childhood through to tertiary. His research interests focus on rural education, PISA data, the effectiveness of moderated learning networks and primary mathematics and technology.

A. Paolino is a lecturer and teaching researcher working in Edith Cowan University's School of Education. Currently, she is teaching in the undergraduate Bachelor of Education (Primary) course. Annamaria conducts and supervises research in Languages/EALD education, education within social settings and using the Arts to facilitate the learning of languages. Prior to becoming a university academic, Dr Paolino was a primary classroom teacher, specialising in Music and Italian for 17 years. She was a Level 3 classroom teacher and has taught across sectors and in metropolitan, rural, remote and online school settings in Western Australia. 
E. V. Slater is a research fellow in the School of Education at Edith Cowan University in Western Australia. Eileen is an early career researcher in the School of Education at Edith Cowan University in Western Australia.with over 20 years' experience as a teacher, school administrator and district curriculum consultant. Her research interests include Science Education, Gifted Education and Educational Measurement. She works closely with the gifted community to advance community and professional understandings of the needs of gifted children. In all of her research projects, Eileen aims to better serve the needs of students by working with and supporting teachers.

J. Boron is a Lecturer in Music Education at Edith Cowan University, Australia. He has studied music education at the University of Western Australia, University of Queensland and the Liszt Academy of Music, Hungary. Jason is a National Council member for the Australian Society for Music Education and National Vice President of the Kodály Music Education Institute of Australia. 